\title{
Desde el norte hacia el sur: esclavizados fugitivos en la frontera texano-mexicana*
}

\author{
MARÍA CAMILA DÍAZ CASAS**
}

\begin{abstract}
From North to South: Enslaved Fugitives in the TexanMEXICAN BORDER. This article studies the conceptions that some enslaved people and slave owners of Texas had about the Mexican-American border between 1821 and 1866. From interviews with enslaved people by agency Works Progress Administration and announcements of escapes published in some Texan newspapers, it was possible to observe that, while the people enslaved understood the border as a space of freedom and social advancement, it also represented a threat to the lifestyle of slave owners. Motivated by this idea, thousands of enslaved people crossed from Texas to Mexico looking for better life conditions and materializing their notions of the border.

Key words: fugitive slaves, abolition of slavery in Mexico, slavery in Texas, Texas enslaved's insights about Mexico
\end{abstract}

\begin{abstract}
Resumen
En este artículo se estudian las concepciones que algunos esclavizados y propietarios esclavistas de Texas tenían sobre la frontera México-Estados Unidos entre 1821 y 1866. A partir de entrevistas realizadas a los esclavizados por la agencia Works Progress Administration y de los anuncios de fugas publicados en algunos periódicos texanos, fue posible observar que mientras los esclavizados concebían la frontera como un espacio de libertad y ascenso social, esto mismo, para sus propietarios, representaba una amenaza a sus condiciones de vida. Motivados por esta idea, miles de esclavizados cruzaron de Texas a México buscando mejores condiciones de vida y materializando sus nociones acerca de la frontera.

Palabras clave: fuga de esclavos, abolición de la esclavitud en México, esclavitud en Texas, percepciones de los esclavizados de Texas sobre México
\end{abstract}

$\mathrm{E}$ n las ciencias sociales, las investigaciones sobre las fronteras han demostrado que éstas son construcciones históricas, producto de un contexto específico, y de ahí la importancia de la historia para pensar estas temáticas. Asimismo, el estudio del concepto de frontera no implica sólo el análisis de los límites territoriales, por el contrario, como demuestra este dossier, existen un sinfín de temas, actores, periodos y enfoques para trabajar dicho concepto. ${ }^{1}$ En este sentido, el interés del presente artículo es indagar cómo los esclavizados del sur de Estados Unidos fueron agentes que intervinieron en la construcción de la frontera y en las relaciones

\footnotetext{
* Artículo recibido el 04/06/17 y aceptado el 13/11/17. Agradezco a la Fundación Slicher van Bath de Jong, al Centro de Estudios y Documentación Latinoamericanos (CEDLA) de Ámsterdam y al Consejo Nacional de Ciencia y Tecnología (Conacyt) por haber financiado la investigación de la cual se derivó el presente texto. Se usa la palabra esclavizados por ser una categoría que responde a una reivindicación social y política la cual connota que las personas no son esclavas por naturaleza, sino que han sido esclavizadas de manera violenta con fines políticos y económicos.

** Escuela Nacional de Antropología e Historia. Periférico Sur y Zapote s/n, col. Isidro Fabela, Tlalpan, 14030, Ciudad de México <mariacamiladc@gmail.com>. orciD: https:/ / orcid.org/0000-0002-5663-7735.

${ }^{1}$ Para una reflexión sobre la definición de frontera en el contexto espaciotemporal estudiado véase Baumgartner (2015).
} 
entre México y Estados Unidos. Con dicho propósito, me concentraré específicamente en explicar cuáles eran las percepciones de los actores locales sobre la frontera entre México y Estados Unidos, en un entorno en el que miles de esclavizados estadounidenses huyeron a México entre 1821 y 1866 . A partir de este estudio, se encontró que los afroamericanos esclavizados en el sur de Estados Unidos construyeron una percepción de la frontera como un espacio que ofrecía libertad y mejores condiciones de vida. Si bien esta concepción sobre la frontera no fue exclusiva de los afroamericanos esclavizados, los propietarios de esclavos y algunos políticos prominentes no la compartieron $\mathrm{y}$, por el contrario, elaboraron una noción diametralmente opuesta, concibiendo el cruce fronterizo como una amenaza para su producción económica, su riqueza (sustentada en la esclavización de miles de personas de origen africano) y el orden social establecido.

La esclavización de personas afrodescendientes en la Nueva España empezó a perder significado económico en gran parte del territorio del virreinato a finales del siglo xviII. La recuperación de la población indígena y de castas a finales de ese siglo, la alta movilidad social y económica de la que gozaron las personas de origen africano y la rentabilidad del trabajo libre provocaron que la esclavitud dejara de tener significación en cuanto forma de producción económica (De la Serna, 1997; Aguirre Beltrán, 1972). Además, desde las primeras actividades insurgentes de Miguel Hidalgo y José María Morelos hubo pronunciamientos en favor de abolir la esclavitud, que fue prohibida en el territorio nacional en 1829 y de manera definitiva en 1837 (Díaz Casas, 2015).

Para el siglo xix, el escaso valor económico de la esclavitud en gran parte de los estados contrastaba con el incremento paulatino del número de afrodescendientes esclavizados en la provincia mexicana de Texas. Allí, desde 1821, se estableció la colonia del empresario Stephen Austin, que después alcanzaría una gran riqueza basada, sobre todo, en la explotación ganadera, de azúcar y de algodón, con mano de obra esclavizada (Sprague, 1939; Vázquez, 2010).

El 15 de septiembre de 1829, el presidente Vicente Guerrero sancionó una ley de abolición de la esclavitud que causó gran controversia. De hecho, los colonos texanos se inconformaron y, en menos de tres meses posteriores a la promulgación la ley, lograron que se declarara una exención al estado de Coahuila-Texas. Gran parte de las élites políticas mexicanas se pronunciaron en contra de la perpetuación de la esclavitud en Texas y, como se verá más adelante, presionaron por cambiar la situación. Este y otros conflictos entre el Estado central mexicano y los colonos texanos ra- dicalizarían sus divisiones, provocando que en 1836 estallara la guerra de independencia de Texas, la cual terminó en su constitución como República independiente.

La persistencia de la esclavitud en la nueva República texana y la postura abolicionista de México originaron la construcción de una concepción sobre este país como un espacio para obtener libertad y mejores condiciones de vida, por lo tanto, miles de personas esclavizadas cruzaron la frontera motivadas por dicha percepción sobre México. La noción del vecino del sur como un país que ofrecía un mejor futuro circuló entre agentes del estado, propietarios esclavistas y entre los mismos afrodescendientes libres y esclavizados, y esto hizo que dichos afrodescendientes asociaran la frontera con una promesa de libertad, que en ocasiones se convirtió en realidad.

En este texto se analizarán las percepciones de los esclavizados y de los propietarios esclavistas sobre la frontera, a través de fuentes como periódicos texanos y las narrativas de los esclavizados, registradas en el siglo xx por la agencia estatal Work Projects Administration (también denominada Works Progress Administration).

\section{La abolición de la esclavitud en México y la independencia de Texas}

En la Nueva España, el proceso de abolición de la esclavitud se inició con las proclamas del bando insurgente en 1810, durante la guerra de Independencia. Tanto Miguel Hidalgo como José María Morelos se pronunciaron en varias ocasiones sobre este asunto. Entre ellas cabe destacar el discurso "Los sentimientos de la nación", de Morelos, donde se expresaron puntos (como la abolición de la esclavitud y de las distinciones de castas) que años después serían jurados en la Constitución de Apatzingán. Debido a que el bando insurgente no fue el que ascendió al poder después de la Independencia en 1821, el proceso de abolición de la esclavitud tuvo que esperar hasta 1829, cuando el presidente Vicente Guerrero promulgó un decreto al respecto (que perdería vigencia en meses posteriores debido al golpe de Estado de Anastasio Bustamante y a la declaración de ilegitimidad del gobierno de Vicente Guerrero por parte del Congreso). Por esta razón, no fue sino hasta 1837 que se aboliría de manera definitiva la esclavitud en México. En 1824 se incluyó en la Constitución la prohibición del comercio de esclavos en territorio mexicano y la declaración de libertad a quienes arribaran a México en calidad de esclavizados (Díaz Casas, 2015). Además, el carácter federalista de 
la Constitución propició que cada estado tuviera la posibilidad de redactar su propio documento constitucional, por consiguiente, en vista de que la regulación sobre los derechos y garantías individuales se reservó a la soberanía local, las 19 constituciones elaboradas en los estados tocaron el tema de la esclavitud; ésta se prohibió definitivamente en Chiapas, Durango, Michoacán, Querétaro, Guanajuato, Tamaulipas y Jalisco (que también proscribió la servidumbre humana). En Coahuila-Texas, Nuevo León, México, Puebla, Zacatecas, Tabasco, Yucatán y Oaxaca sólo se prohibió el tráfico. Mientras que la libertad de vientres fue declarada por Coahuila-Texas, Chihuahua, Nuevo León, Oaxaca, México, Tabasco, Veracruz, Puebla y Yucatán; y las manumisiones fueron contempladas por Michoacán, Nuevo León y Oaxaca, en algunos casos con indemnización a los propietarios. A pesar de las variaciones entre unidades federativas, de lo anterior puede deducirse que quienes redactaron estas disposiciones buscaban una abolición paulatina, alimentada por la libertad de vientres y la prohibición del tráfico, para no afectar directamente el derecho de propiedad de los dueños (Arenal, 1994: 19-21).

Durante el Imperio mexicano se volvió más urgente la necesidad de poblar el norte debido a las amenazas que sobre el territorio ejercían potencias como Inglaterra y Francia y a causa de los constantes ataques de indígenas y filibusteros, además de su ubicación limítrofe con Estados Unidos, nación que se había anexado un territorio enorme a finales del siglo xviI e inicios del xIx. En esa coyuntura, en 1819, Moses Austin, residente de Luisiana bajo el dominio español, inició trámites con la Corona española para establecerse en Texas con 300 familias. En 1821, aún siendo Nueva España, la Diputación Provincial de las Provincias Internas aceptó su solicitud; sin embargo, Moses murió y el proyecto fue retomado por su hijo Stephen (Vázquez, 2010).

El sucesor de Moses estableció las primeras familias en San Antonio Béjar en 1821, mientras el Plan de Iguala se juraba en la Nueva España. Cuando regresó a Texas con un segundo grupo le fue sugerido ir a ratificar su concesión debido a los cambios políticos, así que se dirigió a la Ciudad de México en 1822. Al formarse la Comisión de Colonización en la Junta Provisional Gubernativa del Imperio mexicano, se discutieron varios proyectos de colonización de angloamericanos y mexicanos, lo que no impidió que a Austin se le confirmara el permiso para llevar a cabo su proyecto; pero, nuevamente los cambios políticos iban a alterar la colonización de Texas, pues el Imperio mexicano cayó y se conformó un régimen federal. De este modo, Austin tuvo que esperar a que en 1823 se sancionara una nueva Ley de Colonización y obtener plena autorización para sus planes (Vázquez, 2010).

Desde el establecimiento de la colonia de Austin, la esclavitud en la zona empezó a crecer de modo paulatino. Antes de la existencia de la colonia, las cifras muestran que la esclavización de personas de origen africano no era numerosa, de hecho, la región estaba escasamente poblada y los intentos de colonización previos habían sido menores. Por ejemplo, para 1785 , San Antonio, Nacogdoches y La Bahía representaban una población de 2919 personas y, de ese total, 43 fueron identificadas como esclavos. A principios del siglo xIx, en 1809, el censo señaló la existencia de 33 esclavos en Nacogdoches, y en San Antonio y La Bahía no se registró ninguno; en 1819, sólo se nombran nueve personas de origen africano en los tres asentamientos (Campbell, 1998: 11).

En contraste, cuatro años después de que se establecieron las primeras familias de la colonia de Austin, se contabilizaron 69 familias colonas que poseían esclavos, así como 443 esclavizados de origen africano, que constituían aproximadamente $25 \%$ de una población total de 1800 personas. Randolph Campbell apunta que los registros sobre esclavizados no son muy confiables, no obstante, afirma que en Nacogdoches y el Red River tuvieron una presencia numerosa, que se iría incrementando en el transcurso de la primera mitad del siglo xix (Campbell, 1998: 2-14).

En su mayoría, el establecimiento de colonos anglosajones dependía en alto grado de la mano de obra esclavizada, razón por la cual la emancipación de los esclavos en territorio mexicano en 1829 iba a representar un problema económico que los colonos no tomarían pacíficamente. La ley de abolición de la esclavitud sancionada por el presidente Vicente Guerrero fue recibida el 16 de octubre, un mes después de expedida, en San Antonio de Béjar. En vista de los peligros que conllevaba para la legitimidad del gobierno, el jefe departamental Ramón Músquiz retuvo la publicación del decreto y escribió al gobernador de Texas-Coahuila, pidiendo que solicitara la exención de Texas de esta norma. Su argumento era que las leyes de colonización habían consagrado el derecho a la propiedad de los inmigrantes y los esclavos eran de su posesión antes de llegar a México. También envió una misiva a Stephen Austin, quien había gestionado el permiso de colonización con el gobierno mexicano, informándole del decreto y solicitándole que lo guardara en secreto por un tiempo (Sprague, 1939: 105).

Aun así, el decreto llegó a manos del alcalde de Nacogdoches y el comandante militar local escribió a sus superiores en San Antonio pidiendo información sobre qué responder a las preguntas de los pobladores 

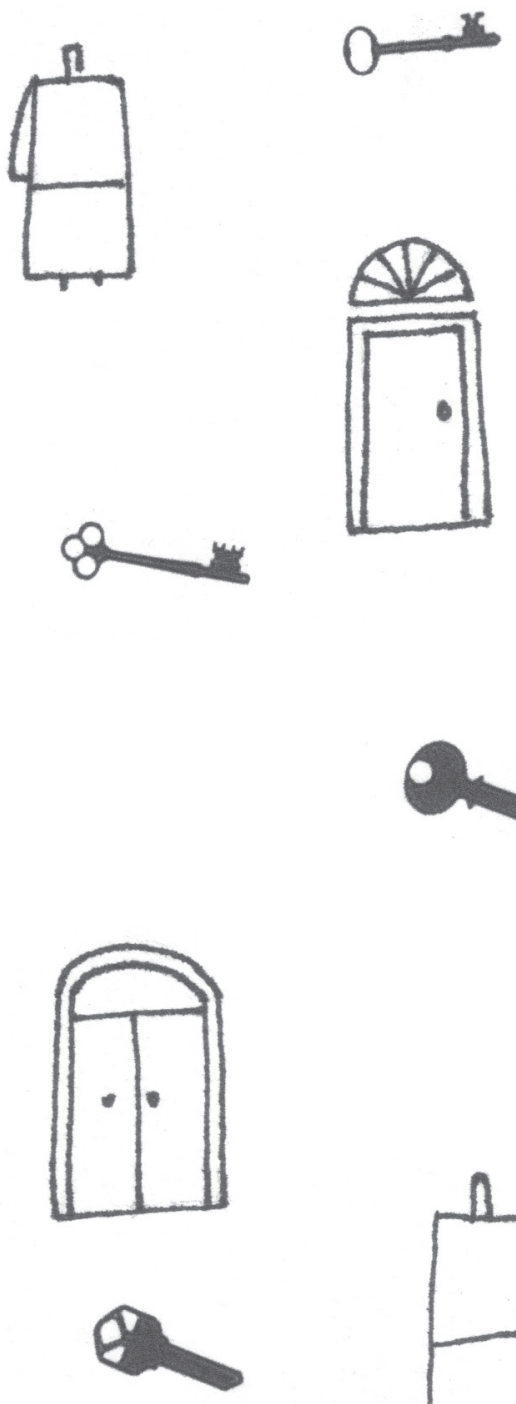

sobre un rumor al respecto. Austin respondió a la carta de Músquiz que era deber de los colonos de Texas recordarle al gobierno el derecho de propiedad estipulado en las leyes de colonización, y que la Constitución del estado reconocía la propiedad en esclavos. El gobernador de Texas y Coahuila envió una comunicación a la Ciudad de México pidiendo la exención de esta provincia en dicho decreto, afirmando que el desarrollo del estado dependía en gran medida de Texas y diciendo que el decreto podría producir disturbios que no se iban a poder controlar (Sprague, 1939: 106).

Después de varias gestiones, el 2 de diciembre, sólo tres meses después de la publicación de la ley de abolición, el presidente Guerrero mandó una carta a Manuel Mier y Terán ordenándole que avisara que Texas iba a ser exentada de la ley. A su vez, Mier y Terán escribió a Stephen Austin notificándole la decisión del gobierno central. Con la circulación del decreto de
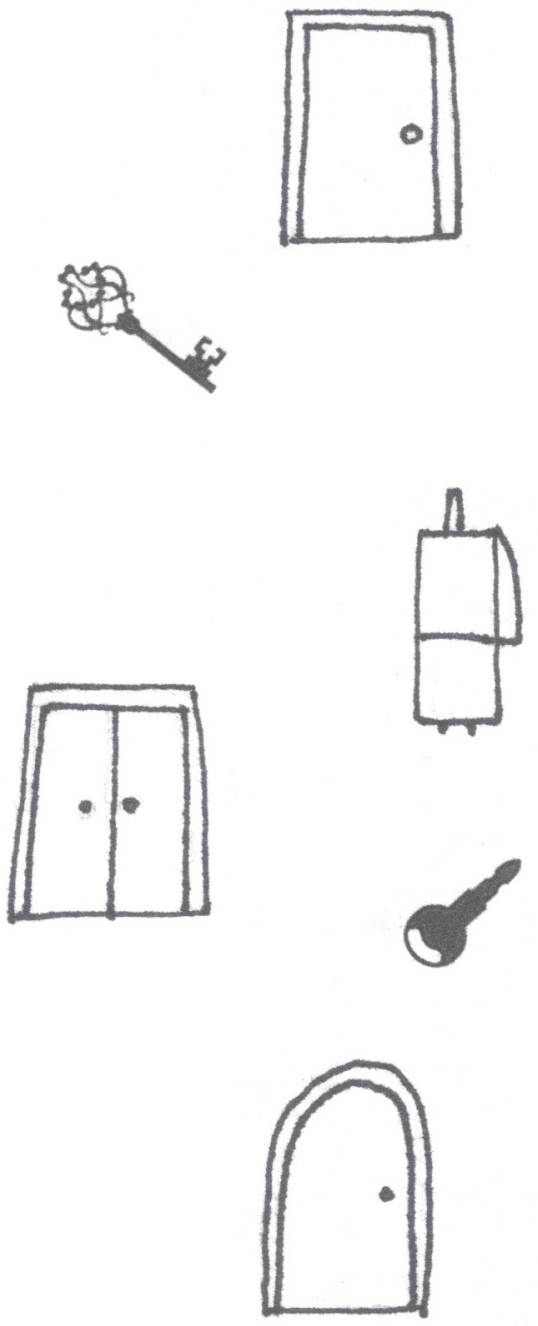

abolición de la esclavitud fue posible observar cómo las élites decimonónicas utilizaron de forma ambigua el discurso sobre los afrodescendientes y la esclavitud, con el fin de prevenir una revuelta de los colonos tejanos. Aun así, el gobierno mexicano no detuvo su lucha por abolir la esclavitud en todo el territorio.

En abril de 1830 los oficiales mexicanos intentaron rectificar la situación con una ley que prohibía la inmigración extranjera en la frontera norte y prohibía la introducción de esclavos a estos territorios, aunque reconocía la existencia de esclavos en Texas (Jiménez Ramos, 2009: 123). Intelectuales como Lucas Alamán, quien se desempeñaba como secretario de Estado, hizo varios intentos por evitar que los colonos de la provincia siguieran introduciendo esclavos, sin embargo, los propietarios encontraron formas de violar la ley, hasta que estalló la crisis que terminó con la separación de la provincia de Texas en 1836 y su anexión a los 
Estados Unidos de América en 1845. Cabe resaltar que, durante la guerra de independencia de Texas, parte de los argumentos en favor de la secesión fueron la falta de garantías del gobierno mexicano para proteger la propiedad privada que, por supuesto, incluía a los esclavizados (Vázquez, 2010).

Con la independencia de Texas en 1836, la esclavitud continuaría siendo una práctica legal en la nueva República, y de ese modo quedó expresado en la Constitución que, en su artículo $1^{\circ}$, sección 9 , decretó que todas las "personas de color" que hubieran sido esclavos antes de su migración a Texas y se mantuvieron en esa condición, continuarían en el estado de servidumbre que decidiera quien reclamaba su propiedad. Asimismo, estipuló los derechos de los inmigrantes de traer esclavos a Texas y prohibió cualquier acto de liberación de los mismos sin el permiso del Congreso de la República (Campbell, 2010). En cuanto a los afrodescendientes libres, el nuevo gobierno aprobó un decreto en el que se prohibía la importación e inmigración de "negros" libres a Texas, éstos no podían ingresar a los límites de la República, bajo pena de ser vendidos como esclavizados, por ende, a los libres se les permitió residir en el área sin ciudadanía, ni derechos de propiedad o garantía de continuidad en sus derechos de residencia (Schwartz, 1975). Lo anterior explica cómo los refugiados en México no eran solamente afrodescendientes esclavizados, algunos eran libres que, a pesar de haber obtenido su libertad, sufrían duras restricciones en sus lugares de residencia.

La independencia, la Constitución y el crecimiento económico con mano de obra esclavizada que experimentó Texas fomentaron la expansión de la esclavitud. La mayoría de los migrantes que llegaron a este territorio antes de la guerra de secesión provenían de los estados del sur $(77 \%$ de las cabezas de familia de Texas en 1860 habían nacido en el sur), muchos trajeron consigo esclavizados y replicaron en la colonia aspectos de la esclavitud que habían vivido en sus estados de origen. Más de un cuarto de las familias de Texas poseía esclavos en 1850 y los esclavizados constituían más de $30 \%$ de la población total del estado. Las proporciones de propietarios de esclavos y esclavizados en Texas en la década de los cincuenta eran muy similares a las de Virginia, lo que demuestra que la esclavitud tenía una gran importancia en esta región (tanta como en los otros estados esclavistas de la Unión) (Campbell, 1998: 2).

Desde 1829, en México confluyeron dos dinámicas fundamentales para el tema que aquí interesa: la posición abolicionista de la esclavitud del gobierno mexicano y el incremento de la riqueza en las colonias de Austin en el estado de Coahuila-Texas a partir de la producción con mano de obra esclavizada. Estas situaciones contrastantes detonaron que miles de esclavizados texanos arriesgaran sus vidas y las de sus familias para cruzar la frontera hacia territorio mexicano y así encontrar libertad y mejores condiciones de vida.

Los intentos del gobierno mexicano por acabar con la esclavitud en Texas, sumados a los pronunciamientos abolicionistas dados en México desde 1810, contribuyeron a que los esclavistas sureños, algunos funcionarios del gobierno de Estados Unidos y los mismos afrodescendientes libres y esclavizados construyeran una percepción de México como un país antiesclavista $\mathrm{y}$ en el que las personas no eran diferenciadas por su color de piel. Ya se ha dicho, pero merece resaltarse, cómo esta concepción sobre México y la frontera iba a tener para los esclavizados una connotación de libertad y acceso a mejores condiciones de vida, mientras que para los propietarios esclavistas significaba poner en riesgo el sostenimiento de la esclavitud.

\section{Esclavitud y libertad cruzando la frontera}

En septiembre de 1851, en el condado de Brazoria, Guy. M. Bryan, político y poseedor de esclavos, escribió a su cuñado respondiendo a la propuesta de intercambio de un esclavo por una extensión de tierra. Bryan planeó visitar esa tarde a su cuñado para inspeccionar al esclavo, sin embargo, oyó rumores sobre las intenciones del esclavo de escapar al sur y puntualizó: "The negroe, he has got Mexico in his head", aseverando que quizás por esto no haría el intercambio. La fuente no deja saber si finalmente se hizo la operación, no obstante, es un testimonio interesante sobre la manera en la que los esclavizados residentes en Texas confirieron a la frontera significados de libertad (Bryan to Perry 1851, cit. en Kelley, 2004: 709).

Similar al testimonio anterior poseemos otros registros recaudados en 1937 por la estatal Works Progress Administration (WPA), agencia creada en el marco del New Deal, orientada a realizar obras públicas y actividades culturales contratando a los desempleados que había dejado la Gran Depresión. Entre sus proyectos, puso en marcha el Federal Writer's Project, que tenía como finalidad investigar, a partir de entrevistas, cómo los antiguos esclavizados recordaban sus experiencias de esclavitud. De este modo se recopilaron valiosos testimonios sobre varios temas; no obstante, para lo que a este artículo atañe, nos concentramos en algunas narraciones sobre las fugas a México, con el propósito 
de analizar la forma en que los esclavizados percibían su situación al otro lado de la frontera (WPA, 1941).

Aproximarnos a las concepciones que actores subalternos como los esclavizados tenían sobre la frontera en el pasado presenta algunas dificultades metodológicas. Las voces de estos sectores de la sociedad siempre se encuentran mediadas por relaciones de poder y son producidas en contextos que interfieren en su contenido. Por supuesto, el caso de las fuentes del Federal Writer's Project no es una excepción. Las entrevistas a los antiguos esclavizados se empezaron a realizar en 1937, pero fue hasta 1941 que se llevaron a cabo específicamente para el estado de Texas. En ese momento, los entrevistados eran muy ancianos y muchos de sus recuerdos podían estar afectados por su avanzada edad. El promedio de edad de los declarantes citados en este artículo es de 92 años e incluso, como se verá más adelante, una de ellas dice no recordar "los tiempos duros" de la esclavitud.

Asimismo, es importante considerar que las entrevistas del proyecto se efectuaron en un periodo de fuerte segregación y racismo, muchos de los entrevistadores eran blancos y esto creaba temor en los antiguos esclavizados, que quizás omitieron información en sus relatos, sobre todo la comprometedora (relacionada con fugas y situaciones complicadas).

Con todo y estas aclaraciones, creo que es muy significativo que, después de más de 70 años de haber abolido la esclavitud en Estados Unidos, de la edad avanzada de los esclavizados y de la mediación en los relatos que producía el contexto del sur estadounidense, persistiera la concepción de México en cuanto país para adquirir la libertad y mejores condiciones de vida. Esto nos deja ver que dicha idea no fue abstracta y excepcional, por el contrario, como descubriremos en los testimonios citados, en la vida cotidiana de las plantaciones texanas los esclavizados compartían este pensamiento y para muchos se convirtió en un proyecto que hicieron realidad cruzando la frontera.

En el volumen dedicado a los antiguos esclavizados del estado de Texas realizado por el WPA en 1941, el exesclavo Felix Haywood dio su testimonio en su casa en San Antonio, allí afirmó haber nacido en St. Hedwig, condado de Bexar, en 1845 y declaró:
Algunos de ellos (los abolicionistas) llegaban y nos animaban a escapar hacia el norte para alcanzar la liberación. Nosotros nos reíamos de ello. No había razón para huir hacia el norte, todo lo que teníamos que hacer era caminar, pero caminar hacia el sur, donde obtendríamos la libertad tan pronto cruzáramos el río Grande. En México se podía obtener la libertad, no les importaba de qué color fuera tu piel, negra, blanca, amarilla o azul. Cientos de esclavos huyeron hacia México y les fue bien. Supimos de ellos y de que se hicieron mexicanos. Criaban a sus hijos para que hablaran sólo mexicano ${ }^{2}$ [WPA, 1941, vol. 2: 132].

El relato de Haywood revela una percepción de México no sólo como un lugar más cercano para alcanzar la libertad, sino en donde existían posibilidades de ascenso social, dado que no importaba el color de piel, contrario al caso de Texas. Como se vio en líneas anteriores, desde la constitución independiente de Texas fueron impuestas duras restricciones para los afrodescendientes libres, por lo tanto, el ascenso social casi siempre estaba fuera de su alcance.

Otro exesclavizado nacido en el condado de San Patricio, Texas, fue entrevistado por WPA en su residencia en Forth Worth. Su nombre era Walter Rimm y en su narración se refirió, entre otros aspectos, a la huida de varios de sus compañeros de plantación y las maneras en las que eran perseguidos con perros y patrulleros. En uno de los ejemplos que dio afirmó: "Un día estaba en el bosque y me encontré con el negro fugitivo. Él vino a nuestra vivienda y mi mamá le dio un sándwich de huevo y tocino y nunca lo volvimos a ver. Quizás se fue hacia México, a donde muchos esclavos huyeron"3 (WPA, 1941, vol. 3: 249).

James Boyd, exesclavizado entrevistado a los 100 años en Itasca, Texas, era originario de una aldea indígena de Phantom Valley, Oklahoma, y contó lo siguiente:

Los esclavos huían y trataban de llegar al norte, pero muchos ladrones de negros los atrapaban y los vendían nuevamente, quizás a peores manos. Muchos de ellos se quedaban alrededor de nosotros en el campo, incluso un negro que quería escapar se dirigía a México. Ése era el cielo de los negros por esos días, ellos pensaban, pero

2 Las traducciones de este y los demás testimonios incluidos son mías. La frase en idioma original dice: "Sometimes someone would come 'long and try to get us to run up North and be free. We used to laugh at that. There wasn't no reason to run up North. All we had to do was to walk, but walk South, and we'd be free as soon as we crossed the Rio Grande. In Mexico you could be free. They didn't care what color you was, black, white, yellow or blue. Hundreds of slaves did go to Mexico and got on all right. We would hear about 'em and how they was goin'to be Mexicans. They brought up their children to speak only Mexican".

3 La frase en idioma original dice: "One day I's in de woods and meets de nigger runawayer. He comes to de cabin and mammy makes him a bacon and egg sandwich and we never seed him again. Maybe he done got clear to Mexico, where a lot of de slaves runs". 
tan pronto como la libertad llegó, yo pensé que debería intentarlo y conseguirme a una esposa mexicana rica y vivir como un gran parásito, pero todo lo que obtuve lo hice trabajando duro ${ }^{4}$ [Crew, Bunch y Price, 2014: 961].

Estos tres testimonios nos muestran la concepción de México y la frontera como un lugar de libertad y ascenso social que, en un contexto de opresión y racismo, se transformaba en una promesa de alcanzar una vida diferente. En estos espacios cotidianos de las plantaciones de Texas los esclavizados hablaban de México como el "cielo de los negros" y el lugar en el cual los esclavizados y sus hijos podían vivir mejor, porque no importaba el color de piel. Incluso me parece muy interesante que aún en el siglo xx persistiera esta idea sobre México y que quedara plasmada como parte de las memorias de esclavización en Estados Unidos.

Los antiguos esclavizados entrevistados por WPA también nos ofrecieron historias que se refieren a México como un sitio de refugio durante la guerra de secesión estadounidense. Según las palabras de algunos de ellos, muchos libres y esclavizados esperaron la abolición de la esclavitud el 19 de junio de 1865 en Texas, para volver con sus familias o a buscar mejores condiciones de vida, bajo la libertad recién adquirida.

Sally Wroe, nacida en una plantación cercana a Austin, fue entrevistada a sus 81 años en una pequeña propiedad rural que poseía en las afueras de la actual capital de Texas, allí vivía con una de las 11 hijas que tuvo después de haberse casado en 1874 . Wroe contaba que sus padres eran recolectores de algodón de la plantación del señor Burdette, a quien describía como un hombre rudo y cruel. En medio de su descripción, Wroe mencionó una ocasión en la que su padre, con otros esclavizados de la plantación, debía llevar algodón en un carro de tracción animal a Brownsville, donde se encontrarían con su amo Burdette. Una vez en el río Grande, los esclavizados tiraron los carros y el algodón al río y se fueron a México, donde vivieron durante la guerra. Wroe finaliza su relato precisando que ella y su madre permanecieron en la casa de Burdette hasta el regreso de su padre, de quien afirmaba había vivido bien en México y aprendió a hablar igual a los mexicanos (WPA, 1941, vol. 4: 224). ${ }^{5}$

$\mathrm{El}$ caso de Bill Thomas fue un poco diferente. Thomas fue entrevistado en un antiguo asentamiento de esclavos cerca a Hondo, Texas, vivía con su esposa Ellen. Poseían una pequeña extensión de tierra y, según el entrevistador, parecían ser felices. Thomas fue comprado a los cinco años en el condado de Falls junto con su madre y hermanas por el señor Chamblin, de quien dice los alimentaba bien y solamente lo azotó una vez, sin hacerlo sangrar. ${ }^{6}$ Thomas narró cómo obtuvo la libertad. Durante la Guerra Civil su amo lo llevó a México, donde vendió algodón que había comprado en Texas a muy buen precio y lo dejó libre a los 14 años. Allí vivió, trabajó como cocinero en un hotel durante dos años y, presumiblemente, después de la Guerra Civil volvió a Texas, donde fue entrevistado en el siglo xx. Su esposa Ellen, oriunda de Misisipi, relataba haber llegado esclavizada a Texas cuando era muy pequeña y afirmó no haber oído mucho sobre los "tiempos difíciles", pues su amo fue generoso y ella incluso se quedó con él y su familia después de haber obtenido la libertad después de la Guerra Civil. Entre otros temas de la vida cotidiana, Ellen mencionó nunca haber sido azotada de manera cruel, pero explicó que quienes se fugaban a México y eran atrapados eran azotados terriblemente (wPA, 1941, vol. 4: 86-88). ${ }^{7}$

A partir de los testimonios de Sally Wroe y Bill Thomas pudimos ver cómo, en dos situaciones diferentes, México ofreció un refugio temporal durante la

4 La frase en idioma original dice: "De slaves did run off an' try to go north, but nigger stealers mos' of-fen got dem an den dey would be sold again an maybe git worse hans holt of 'em. Mos' en general 'round our part of de country, effen a nigger want to run away, he'd light out fer ole Mexico. Dat was nigger heaven dem days, dey thought, but soon as de Freedom come, I thought I'd try it an git me a rich Mex wife an live like a big bug, but all I got shore worked hard to get it".

5 La cita textual del testimonio de Wroe es: "Each man was drivin a ox wagon down to Brownsville, where day was to wait to meet Massa Burdette. But pappy and da others left do wagons "long de river "bank and rolled a "bale of cotton in de river and all four of der a gits on dat bale and rows with sticks' crossover into Mexico. Dis was durin' de war. Pappy come back to us after freedom and say he don git 'long fine with Mexico. He larnt to talk jts' like dem. Me and mammy stays on at Massa Burdette's place de whole time pappy gone".

6 La cita textual del testimonio de Bill Thomas es: "I'll tell you how I got away f 'om there. Massa, bought cotton and carried it to Mexico. He taken his 2 boys with him and we had 3 wagons and I drove one. I had 4 oxen and I had 3 bales of cotton on my wagon; he had 6 oxen and 6 bales of cotton, and the last wagon, it had 10 bales on it and 6 oxen. He had to ship it acrost the Rio Grande. If a Mexican bought it, he come across and took it over hisself. Reckin how much he got for that cotton? He got 60c a pound. Yes'm, he sho' did. Cotton was bringin' that then. I was freed over there in Mexico. I was about 14 years old. Massa Chamlin, he stayed over there till the country was free. He didn't believe in that fightin'. I cooked in a hotel over there in Mexico. I cooked two years at $\$ 1.00$ a day".

7 La cita textual del testimonio de Ellen Thomas dice: "I never did hear much about hard times. I was treated good but I got switched many a tire. Oh, yes, I've been whipped, but not like some of dem was. They used to tie some of 'em down. I've heered tell, they shore whopped 'em. They used to be a runaway that got away and went to Mexico now and then, and if they caught him they shore whopped him awful". 
Guerra Civil. En el caso de Wroe, su padre escapó a México con otros esclavizados, donde vivió hasta el fin de la guerra, mientras que en el de Thomas, su amo lo liberó en México durante la guerra y éste retornó a Texas al final de la misma.

Los registros de las vidas de los antiguos esclavizados recuperados por WPA nos brindan información valiosa desde la mirada de estos sujetos sobre su percepción de México y la frontera. Parte de los entrevistados explicaban cómo ellos y sus conocidos veían en la frontera una posibilidad de refugio y libertad e incluso muchos cruzaron el río Grande en búsqueda de otra clase de vida. En contraste, la concepción sobre la frontera entre los propietarios esclavistas residentes en Texas era diferente. Para ellos, México significaba una amenaza para la esclavitud y los mexicanos eran cómplices de los esclavizados fugitivos. Por consiguiente, en lo que resta de este artículo realizaré una breve aproximación a la prensa de ciertos condados texanos entre 1845 y 1857, que nos permite diferenciar las visiones de los esclavistas y los esclavizados al respecto de México.

En algunos anuncios tratados en este texto, se denunciaba la fuga de esclavizados y se ofrecían recompensas por su captura y devolución, también se describía a los fugitivos y detalles de su escape. Al igual que los testimonios de los esclavizados, las noticias aquí citadas se produjeron en un contexto particular y están mediadas por intereses económicos y políticos. En este sentido, es probable que muchos denunciantes exageraran las situaciones y crearan un estado de alarma, que quizás no era tan apremiante, para presionar a las autoridades a tomar medidas frente a las fugas y frente a México y garantizar sus privilegios económicos. Aun así, la prensa trabajada proporciona datos relevantes y útiles para aproximarnos a la concepción que los esclavistas texanos tenían sobre la frontera, y contrastarla con la de los afrodescendientes esclavizados. Mientras que para los segundos la frontera connotaba libertad y ascenso social, para los primeros la frontera estaba relacionada con una preocupación por las fugas de esclavizados a México y una idea sobre este país y sus ciudadanos como algo que ponía en peligro sus propiedades y su estilo de vida.

En los periódicos de Texas revisados, correspondientes a varios condados, se reportaron las fugas de esclavizados rumbo a México, narrando que en ocasiones la huida fue frustrada y los esclavizados capturados; no obstante, en otros se quejaban de que cuando los fugitivos cruzaban la frontera ya era imposible recuperarlos. Por ejemplo, el 14 de agosto de 1858, The Colorado Citizen publicó que desde enero de ese año, en el condado de Gillespie, se habían devuelto a sus propietarios 23 esclavizados que pretendían escapar hacia México. Asimismo, se informó que los colonos alemanes de la zona capturaban a muchos de los que intentaban huir al país vecino y se resaltó lo positivo de su presencia en Texas. ${ }^{8}$

Por otro lado, The Texas State Times, del 28 de julio de 1855, reportaba la fuga de dos esclavizados que habían robado caballos a un ciudadano de Bull Creek. ${ }^{9}$ Por su actitud sospechosa, los fugitivos fueron atacados con perros en el camino de huida, aunque de todas maneras lograron su cometido. Más allá de la denuncia de la fuga de los dos afrodescendientes, a lo largo del artículo se manifiesta una preocupación por el número de fugitivos hacia México y llama la atención de los amos para tomar medidas al respecto. En consecuencia, el autor propone apoyar a los liberales que luchan contra Santa Anna con el fin de asegurarse de que la esclavitud persista en Texas y en otros estados. Asegurando que en las últimas semanas se habían fugado más de 20 esclavizados, se sostiene que la venta de éstos habría sido suficiente para pagar un cuerpo armado que ayudara a los oponentes de Santa Anna en México. Finalmente se subraya que el éxodo iba en aumento y que la única forma de evitarlo era hacer arreglos legales para que ambos países se comprometieran a entregar los esclavizados fugitivos. La noticia del The Texas State Times es muy reveladora, pues no sólo registra las fugas, sino que asocia la persistencia de la esclavitud en Texas al entorno político mexicano y a las posibilidades de intervención en una contienda interna, con el fin de garantizar los intereses de los esclavistas del sur de Estados Unidos.

Entre los periódicos que exigían medidas más fuertes para el control de los esclavizados fugitivos a México se encuentra The Texas Monument, del condado de Fayette, que el 26 de febrero de 1851 publicó una carta recibida del condado de Colorado en la que se informaba que varios esclavizados se habían confabulado para escapar a México. Éste fue descubierto y frustrado, aunque uno de los fugitivos logró su objetivo. El plan del grupo era dividirse en pequeñas partidas hasta llegar a San Antonio, donde se encontrarían. En este sentido, el escritor del artículo hace un llamado a que se establezcan puestos de vigilancia en la zona,

\footnotetext{
The Colorado Citizen, condado de Colorado, 14 de agosto de 1858, p. 2.

The Texas State Times, condado de Travis, 28 de julio de 1855, p. 2.
} 
pues esta situación amenaza la propiedad de los ciudadanos esclavistas de Texas. ${ }^{10}$

Asimismo, el Texas Monument de octubre 16 de 1850 reportaba que el sábado previo dos esclavos habían robado caballos y huido hacia México. ${ }^{11}$ Ambos fueron aprehendidos; no obstante, la situación de uno de ellos, de nombre Talbot, fue más complicada, pues ya antes había huido a México (dos años) y regresado voluntariamente en abril del mismo año. Por esa razón, los esclavizados permanecerían con cadenas hasta que fueran vendidos en el interior. Al igual que el periódico del 26 de febrero de 1851, el artículo exhortaba a los dueños de esclavos a estar en guardia para que esto dejara de ocurrir. La prensa pone de manifiesto con claridad cómo la percepción sobre México y la frontera era diametralmente opuesta entre propietarios y esclavistas. Dada esta discrepancia, los segundos llamaban la atención sobre la necesidad de tomar medidas para impedir las fugas, y tales medidas variaban desde intervenciones políticas en los asuntos internos mexicanos, hasta mejorar la vigilancia de los afrodescendientes.
Por otro lado, la prensa de varios condados texanos no sólo asoció a México y a la frontera con los esclavizados fugitivos, también vinculó a los ciudadanos mexicanos con dichas fugas como cómplices o incitadores que debían ser castigados. Por ejemplo, el 18 de enero de 1845, Robert Porter de Falls on the Brazos, condado de Falls, ofrecía 12 dólares de recompensa para recuperar a sus esclavos, que huyeron con cuatro de sus sementales de pura sangre. Porter aseguraba que estaban tratando de llegar a México, encabezados por un "hombre blanco" o un "mexicano" y ofreció 600 dólares de recompensa a quienes entregaran sus propiedades en Falls on the Brazos y a quienes aprehendieran y entregaran a las personas que los sedujeron a huir. ${ }^{12}$

Igualmente, el 8 de abril de 1852, The Texas Monument divulgaba la recompensa de 100 dólares que prometía Patrick Perry del condado de Fort Bend por recuperar a sus esclavos fugitivos. La noticia decía que "4 negros" eran sospechosos de dirigirse a México y afirmaba que varios caballos y un mexicano llamado Phillippi tampoco se encontraban en su lugar,

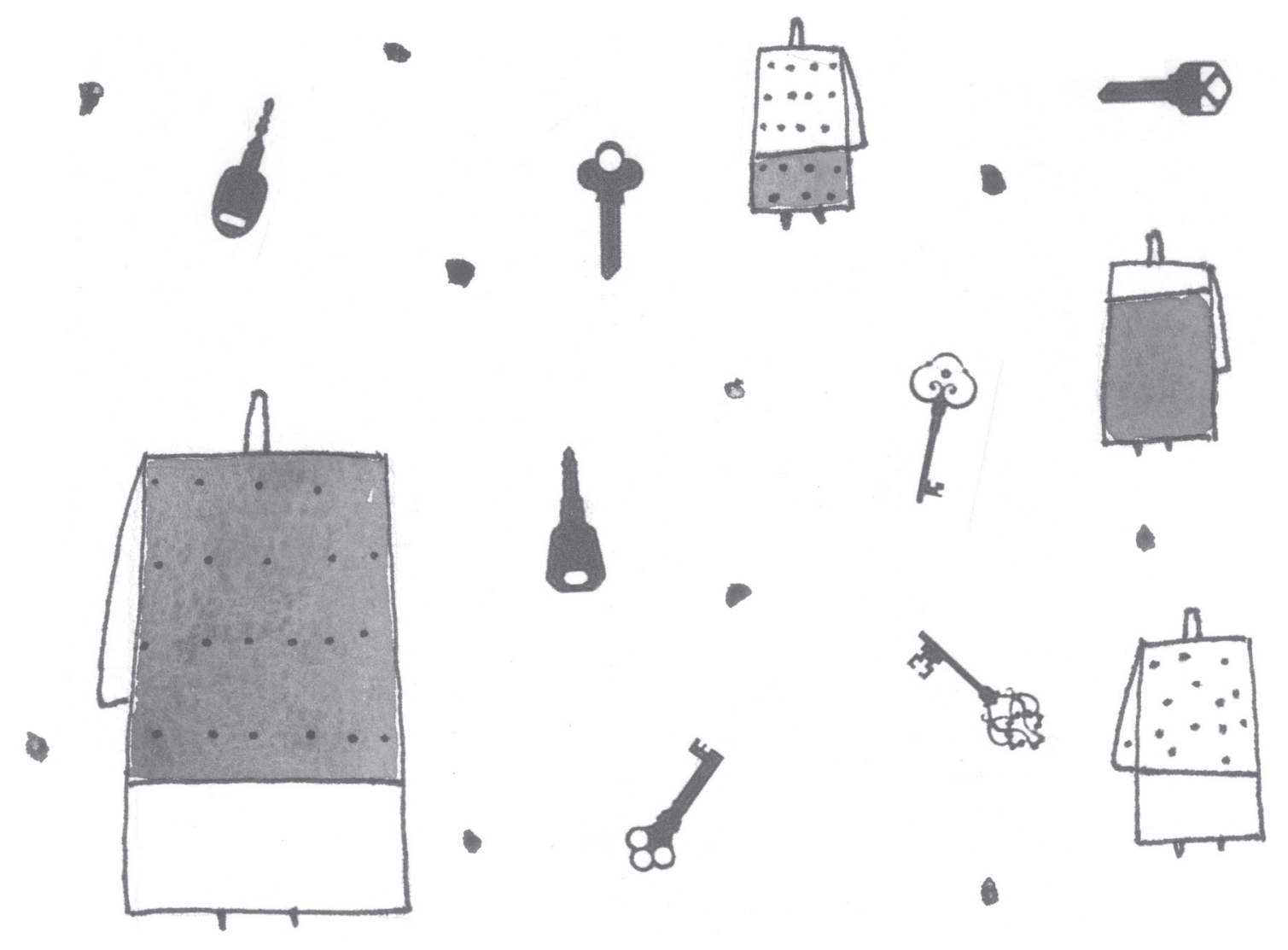

${ }^{10}$ The Texas Monument, condado de Fayette, 26 de febrero de 1851 , p. 1.

${ }^{11}$ The Texas Monument, condado de Fayette, 16 de octubre de 1850 , p. 2.

12 Texas National Register, condado de Falls, 18 de enero de 1845, p. 7. 
proponiendo la posible asociación del mexicano "Phillippi" con los fugitivos. ${ }^{13}$

El 7 de julio de 1842, en el condado de Jackson, un propietario anónimo denunció que un mexicano fue capturado y ahorcado en cercanías a Texana en su intento por escapar con una niña esclavizada, con quien estaba viviendo como esposa, propiedad de un vecino de la ciudad. El mexicano fue detenido y colgado en un árbol y la esclavizada devuelta a su propietario. En la misma nota se decía que otro mexicano había sido descubierto unas semanas atrás cerca de una plantación en San Felipe, cuyo propietario lo apresó y después de interrogarlo concluyó que estaba incitando a varios esclavizados a fugarse a México. El prisionero confesó y el propietario esclavista ordenó a uno de sus esclavos que le cortara las orejas, lo azotara y lo enviara de vuelta por el río Grande. La noticia también denunciaba varias tentativas similares realizadas por mexicanos y que éstos sostenían alianzas con los esclavizados, por ello alertaba a los dueños de plantaciones a vigilar que sus esclavos no fueran seducidos a huir. ${ }^{14}$

Además de acusar a los mexicanos residentes en Texas, otros periódicos, como The Indianola Bulletin del 31 de mayo de 1855, titulaba un artículo desde el condado de Bastrop "More slaves piloted to Mexico by Mexican peons", acusando de manera directa a los peones mexicanos de "seducir" a los esclavizados para que escaparan. En la noticia publicada se describía que un ciudadano de Bastrop informaba que cinco de sus esclavos fueron conducidos a México por dos mexicanos que eran trabajadores de pueblos del oeste de Texas. El periódico se refiere de nuevo a la situación política mexicana, explicando que lo ocurrido era la expresión del injusto tratado con México -refiriéndose al Tratado de Amistad, Navegación y Comercio firmado el mismo año entre las dos naciones-, en donde, según el autor, no se garantizaba la propiedad del esclavizado si éste cruzaba al país vecino. Por lo tanto, se exigía que se introdujera en dicho tratado una cláusula que "haga justicia al estado de Texas y al resto del sur". ${ }^{15}$ Recordemos que el tratado no contemplaba la cláusula a la que alude el periódico, a pesar de que la misma fue introducida al documento en 1825, cuando se iniciaron las discusiones del tratado. Fue debatida en $1831 \mathrm{y}$, al parecer, eliminada ese mismo año. ${ }^{16}$
Otros periódicos hicieron hincapié en el papel de los mexicanos en las fugas. El 21 de octubre de 1854, The Standard, del condado Red River, denunciaba también que los peones mexicanos inducían a los esclavizados a huir y se asociaban con ellos en perfecta igualdad. Se afirmaba que cuando el esclavizado llegaba a México descubría que no había nada y pasaba hambre y miseria, algunos, para sobrevivir, se convertían en peones y experimentaban condiciones más desfavorables de las que vivían bajo el dominio de su propietario. Explicaba el periódico que bajo la esclavitud el individuo recibía carnes, pan, ropas y cuidado médico, mientras que como peón en México sufría hambre, era brutalmente utilizado, vestía mal y no era visto por ningún doctor si enfermaba. El autor del artículo consideraba que los peones mexicanos eran peligrosos para los esclavos y sostenía que huyendo a México éstos reclamaban los privilegios civiles de un hombre blanco y se convertían en instrumento del mal. ${ }^{17}$

The Bastrop Advertiser, del condado del mismo nombre, retomaba en 1858 una noticia del San Antonio Herald que anunciaba el descubrimiento de una conspiración entre dos mexicanos y varios esclavizados que hacían arreglos para que los segundos huyeran a México. La fuga fue develada antes de que se realizara en Gonzales, aun así, los mexicanos huyeron y, de acuerdo con el autor, al parecer no volverían a ser una molestia para los esclavistas de la región. ${ }^{18}$

Del mismo modo, The Texas Monument, del condado de Fayette, publicó el 23 de abril de 1851 que en Eagle Pass un hombre joven había capturado a un esclavizado fugitivo, propiedad de su hermano. ${ }^{19}$ James Barlett, como se llamaba el hombre, fue a Presidio, Río Grande, a capturarlo, y allí se lo compró a un mexicano, no obstante, el esclavizado mató a Barlett y huyó de nuevo a México en compañía del mexicano. Denunciaba, igualmente, que el ciudadano J.H. Brown llegó a Eagle Pass con dos esclavizados fugitivos que habían vivido un tiempo en México.

El contraste de fuentes que nos hablan sobre dos grupos de población claramente diferenciados por su posición social, política y económica nos permite analizar cómo los mismos construyeron concepciones opuestas sobre su entorno. La cercanía de Texas con México, las diferencias existentes en cuanto a la

\footnotetext{
13 The Texas Monument, condado de Fayette, 8 de abril de 1852 , p. 3.

${ }^{14}$ The Red Lander, condado de Jackson, 7 de julio de 1842, p. 4.

15 The Indianola Bulletin, condado de Bastrop, 31 de mayo de 1855, p. 2.

${ }^{16}$ Un desarrollo más extenso sobre el tema se encuentra en mi tesis doctoral en proceso, titulada “'In Mexico you could be free, they didn't care what color you was': Afrodescendientes, esclavitud y libertad en la frontera entre México y Estados Unidos, 1821 -1866" (Escuela Nacional de Antropología e Historia, México).

17 The Standard, condado Red River, 21 de octubre de 1854, p. 4.

18 The Bastrop Advertiser, condado Bastrop, 5 de junio de 1858, p. 2.

19 The Texas Monument, condado de Fayette, 23 de abril de 1851 , p. 1.
} 
esclavización de personas afrodescendientes y el proceso de abolición de la esclavitud en ambas orillas del río Grande, configuraron una serie de percepciones particulares de cada grupo sobre la frontera y sobre México.

Según los testimonios de los esclavizados, registrados por WPA en el siglo xx, en las plantaciones $\mathrm{y}$ en las ciudades de Texas se pensaba a México y a la frontera como un lugar en el que era posible terminar con la situación de esclavitud y alcanzar mejores condiciones de vida. También se consideró a México un refugio durante la Guerra Civil en Estados Unidos y se narraban casos de amigos o conocidos que, en México, vivían con menos restricciones que las impuestas por las leyes texanas. De hecho, era tal la magnitud de esta percepción que los esclavizados entrevistados en 1941 aún preservaban la idea de México como un sitio de refugio, la cual, además, quedó plasmada como parte de las memorias de la esclavización rescatadas por medio de este proyecto gubernamental.

Examinar la prensa de algunos condados de Texas entre 1845 y 1852 permitió observar la percepción de México como una amenaza al sistema político, social y económico sustentado en la esclavitud en varios estados del sur de Estados Unidos. En Texas, específicamente, se narraban las fugas de los esclavizados, se ofrecían recompensas, se anunciaba que los fugitivos habían robado caballos y otros elementos; sin embargo, también se hablaba de la necesidad de intervenir en la política mexicana para garantizar la esclavitud, y del peligro que representaban los mexicanos residentes en Texas, quienes fueron catalogados como cómplices o incitadores de los escapes.

La concepción de México como un país de refugio para los esclavizados no fue abstracta. De hecho, entre 1821 y 1866 el Estado mexicano desplegó una retórica de cobijo a los esclavizados estadounidenses, expresada a través de la voz de varias personas públicas y de algunos artículos de opinión en la prensa nacional. ${ }^{20}$ Además, no cedió ante las presiones diplomáticas y políticas ejercidas por Estados Unidos. Un ejemplo de ello fue el intento de Estados Unidos de que se incluyera la cláusula del esclavo fugitivo (que obligaba al gobierno mexicano a devolver a los fugitivos que se encontraban en su territorio) en el Tratado de Amistad, Navegación y Comercio que se empezó a negociar en 1825 y que finalmente fue firmado en la década del cincuenta, aunque en su versión final no se formalizó la cláusula mencionada. Lo anterior no quiere decir que en las vidas cotidianas de los refugiados en México esta retórica de protección se hiciera efectiva. Gracias al acercamiento a varias fuentes, es posible observar una gran diversidad de historias, unas de éxito y otras de regreso a Texas, entre quienes lograron instalarse en territorio mexicano. ${ }^{21}$

En suma, la frontera entre México y Estados Unidos, en este caso específico entre Texas y México, constituye un espacio muy interesante para pensar la presencia de población de origen africano en el continente americano. Gracias a las dinámicas ocurridas en esta región durante el siglo xIX podemos entender que dicha presencia trascendió las fronteras nacionales y, por ende, los investigadores debemos replantear estos límites contemporáneos para pensar problemas del pasado. Igualmente, los casos de los esclavizados fugitivos hacia México nos dejan ver cómo, a pesar de las fuertes restricciones, las personas de origen africano vieron en la frontera una oportunidad de mejorar su vida y, en concordancia, cruzaron el río Bravo perseguidos por sus propietarios o por cazadores de esclavos, y atacados con perros y armas de fuego. También es posible observar cómo México ofreció una posibilidad de resistencia a la esclavitud, representando una opción de libertad y ascenso social, en un contexto de fuerte racismo y opresión.

Al inicio de este artículo señalé que la frontera es una construcción histórica y, por ello, creo esencial reiterar la importancia del análisis histórico y etnohistórico para pensar la emergencia y consolidación de las mismas en contextos temporales y espaciales específicos.

Para finalizar, debo mencionar que, en contraste con lo ocurrido en el siglo xIx y de las fugas de norte a sur, la situación actual es muy distinta. Miles de afromexicanos de la Costa Chica de Guerrero y Oaxaca han migrado a Estados Unidos en busca de una vida mejor (Quecha, 2016), asimismo, miles de haitianos están viviendo en condiciones infrahumanas en estados limítrofes del norte de México, afectados por el endurecimiento de las políticas migratorias en la era Trump. Las diferencias en los contextos señalados evidencian la historicidad de las fronteras y su carácter de espacios sociohistóricos en disputa, que se encuentran en constante transformación. ${ }^{22}$

${ }^{20}$ Véase mi trabajo de tesis doctoral (en proceso), ya citado.

${ }^{21}$ Para ampliar más ejemplos al respecto de la actuación del Estado mexicano frente a las fugas véase mi tesis de doctorado en proceso de elaboración.

${ }^{22}$ Las reflexiones al respecto de la historicidad de las fronteras han sido motivadas por sugerencias realizadas por los revisores de este artículo, a quienes agradezco sus amables comentarios y sugerencias. 


\section{Fuentes primarias}

Texas National Register, Falls County, 18 de enero de 1845. The Bastrop Advertiser, Bastrop County, 5 de junio de 1858. The Colorado Citizen, Colorado County, 14 de agosto de 1858. The Indianola Bulletin, Calhoun County, 31 de mayo de 1855. The Red Lander, Jackson County, 7 de julio de 1842.

The Standard, Red River County, 21 de octubre de 1854. The Texas Monument, Fayette County, 16 de octubre de 1850. The Texas Monument, Fayette County, 26 de febrero de 1851. The Texas Monument, Fayette County, 23 de abril de 1851. The Texas Monument, Fayette County, 8 de abril de 1852. The Texas State Times, Travis County, 28 de julio de 1855.

\section{Otras fuentes}

Aguirre Beltrán, Gonzalo

1972 La población negra en México. Un estudio etnohistórico, Fondo de Cultura Económica, México, $374 \mathrm{pp}$.

Arenal Fenochio, Jaime Del

1994 "La utopía de la libertad: la esclavitud en las primeras declaraciones mexicanas de derechos humanos", en Anuario Mexicano de Historia del Derecho VI-1994. La tradición indiana y los orígenes de las declaraciones de derechos humanos, núm. 6, Instituto de Investigaciones Jurídicas-Universidad Nacional Autónoma de México, México, pp. 3-24.

Baumgartner, Alice

2015 "The Line of Positive Safety: Borders and Boundaries in the Rio Grande Valley, 1848-1880", en The Journal of American History, vol. 101, núm. 4, pp. 1106-1122.

CAMPBEll, RandolPH

1998 A Empire for Slavery. The Peculiar Institution in Texas, 1821-1865, Louisiana University Press, Baton Rouge y Londres, 320 pp.

\section{CAmpBell, RANDOLPH}

2010 The Laws of Slavery in Texas. Historical Documents and Essays, University of Texas Press, Austin.

Crew, Spencer, Lonnie Bunch

y Clement Price (eds.)

2014 Slave Culture: A Documentary Collection of the Slave Narratives from the Federal Writers, Project Greenwood, Santa Bárbara.
Díaz Casas, María Camila

2015 ¿De esclavos a ciudadanos? Matices sobre la ‘integración' y ‘asimilación' de la población de origen africano en la sociedad nacional mexicana, 1810-1850", en Juan Manuel de la Serna (coord.), Negros y morenos en Iberoamérica. Adaptación y conflicto, Centro de Investigaciones sobre América Latina y el Caribe-Universidad Nacional Autónoma de México, México, pp. 273-304.

JimÉnEZ RAMOS, MARISELA

2009 Black Mexico: Nineteenth Century Discourses of Race and Nation, Brown University, Rhode Island, $268 \mathrm{pp}$.

Kelley, SeAn

2004 "Mexico in his Head": Slavery and the TexasMexico Border, 1810-1860", en Journal of Social History, vol. 37, núm. 3, pp. 709-723.

Quecha Reyna, Citlali

2016 Familia, infancia y migración: un análisis antropológico de la Costa Chica de Oaxaca, Instituto de Investigaciones Antropológicas-Universidad Nacional Autónoma de México, México, 208 pp.

SchWARTZ, RosaliE

1975 Across the Rio toFreedom:U.S. Negroes in Mexico, Texas Western University Press, El Paso, 64 pp.

Serna, Juan Manuel de la

1997 "La esclavitud africana en la Nueva España. Un balance historiográfico comparativo", en María Guadalupe Chávez Carbajal (coord.), El rostro colectivo de la nación mexicana, Universidad Michoacana de San Nicolás de Hidalgo, México, pp. 249-284.

Sprague, William

1939 Vicente Guerrero Mexican Liberator. A Study in Patriotism, R.R. Donnelley \& Sons, Chicago, $178 \mathrm{pp}$.

VÁZguez, Josefina Zoraida

2010 México y el mundo. Historia de sus relaciones exteriores. México y el expansionismo norteamericano, t. I, El Colegio de México, México, $244 \mathrm{pp}$.

Work Project's Administration

1941 Slaves Narratives. A Folk History of Slavery in the United States from Interviews with Former Slaves. Texas Narratives, vols. 1-4, Work Project's Administration, Washington. 